\title{
ImproveCog, a cognitive stimulation program for people with mild cognitive impairment and dementia: First stage of development
}

\author{
Laura Meireles ${ }^{(D)} 1,2, \&$ Selene G. Vicente 2,3 \\ ${ }_{1}$ Serviço de Psicologia do Departamento de Saúde Mental do Hospital Pedro Hispano - Unidade Local de \\ Saúde de Matosinhos, EPE \\ ${ }^{2}$ Faculdade de Psicologia e de Ciências da Educação da Universidade do Porto \\ ${ }^{3}$ Centro de Psicologia da Universidade do Porto
}

\begin{abstract}
Cognitive stimulation seems to be an important tool to slow the rate of cognitive decline due to dementia. This study describes the development of a cognitive stimulation program (ImproveCog) for people with Mild Cognitive Impairment, Alzheimer's Disease, and behavioral variant Frontotemporal Dementia, within the Medical Research Council framework. Stage 1 established the theoretical and evidence basis of the program through a review of the existing cognitive stimulation programs as well as cognitive exercises and their efficacy (Pre-Clinical Phase) and includes qualitative testing through five focus group with eighteen health professionals and twelve individual interviews with people with cognitive impairment (Phase I - Modeling). An initial version of the program, which consisted of twelve 90-min weekly sessions and included a manual with cognitive stimulation exercises to be performed at home, was ready to be implemented in a pilot study to create a final version of ImproveCog.
\end{abstract}

Keywords: Cognitive stimulation program; Systematic approach; Mild cognitive impairment; Alzheimer's disease; Frontotemporal dementia.

ImproveCog, um programa de estimulação cognitiva dirigido a pessoas com Défice Cognitivo Ligeiro e Demência: Etapa 1 de desenvolvimento: A estimulação cognitiva parece ser uma ferramenta útil para atrasar o declínio cognitivo associado à demência. Este estudo descreve o desenvolvimento de um programa de estimulação cognitiva (ImproveCog) para pessoas com Défice Cognitivo Ligeiro, Demência de Alzheimer e Demência Frontotemporal Variante Comportamental, segundo as orientações do Medical Research Council. A Etapa 1 estabeleceu a base teórica e de evidência do programa através da revisão dos programas de estimulação cognitiva e exercícios cognitivos existentes, e respetiva eficácia (Fase Pré-Clínica) e inclui uma avaliação qualitativa através de cinco focus group com dezoito profissionais de saúde e doze entrevistas individuais com pessoas com défice cognitivo (Fase I Modelagem). Uma versão inicial do programa, que consistia em doze sessões semanais de 90 minutos e incluía um manual com exercícios de estimulação cognitiva para realizar em casa, foi elaborada para ser implementada num estudo piloto por forma a criar uma versão final do ImproveCog.

Palavras-chave: Programa de estimulação cognitiva; Abordagem sistemática; Défice Cognitivo Ligeiro; Demência de Alzheimer; Demência Frontotemporal.

The aging of the human population has brought many challenges to the scientific community, especially to ensure that longevity is compatible with cognitive and functional integrity, and quality of life. Aging brings an increased incidence of Mild Cognitive Impairment (MCI) and dementia, such as dementia associated with Alzheimer's Disease (AD) and behavioral variant Frontotemporal Dementia (bvFTD), which have an impact not only on patients' lives but also on those around them. MCI represents an intermediate stage between normal cognitive aging and mild dementia (Petersen et al., 2009; Vega \& Newhouse, 2014) that is characterized by a cognitive decline in one or more cognitive domains and preserved functionality (APA, 2014; Knopman et al., 2003). AD is the most prevalent type of dementia. It can be described by memory, language, gnosis, visuospatial, and executive deficits that occur along with a functional decline. On the other hand, bvFTD is a type of dementia defined by prominent changes in personality, inappropriate social behavior, deficits in planning and execution of everyday activities, language impairment, and apathy (Massano, 2009). ${ }^{1}$ Correspondence address: Laura Meireles, Unidade Local de Saúde de Matosinhos, Rua Dr. Eduardo Torres, 4464-513 Senhora da Hora,
Matosinhos, Portugal. E-mail: laura.meireles@ulsm.min-saude.pt 
According to the World Health Organization (WHO, 2019) and the Lancet Commission on Dementia, Prevention, Intervention, and Care (Livingston et al., 2017), the number of people living with dementia around the world is currently estimated at 50 million and will almost triple by 2050. Dementia should be considered a priority in public health (Livingston et al., 2017; Wortmann, 2012). Although there is no cure for dementia, there are a number of drugs and non-pharmacological interventions that help to slow the progression of the disease and allow patients, caregivers, and families to have a better quality of life. Given the current limitations of pharmacological interventions in dementia, such as achieving absolute symptom control and optimizing therapeutic agents that modify disease progression (Eleti, 2016), there has been a higher focus on the relevant role of non-pharmacological interventions (Mapelli et al., 2013).

\section{Cognitive Intervention}

Cognitive intervention is an effective non-pharmacological approach to deal with cognitive decline (Clare \& Woods, 2004; Léonie et al., 2010; Li et al., 2011; Vidovich \& Almeida, 2011). The concepts of cognitive training, cognitive rehabilitation, and cognitive stimulation are the most well-known types of cognitive interventions (Clare et al., 2003). These complementary types of intervention are frequently used interchangeably, despite having different meanings, objectives, and consequences. The option for one of them depends on the purpose of the intervention and the patient's cognitive profile (Buschert et al., 2010).

Cognitive training involves guided and repeated practice of standard exercises designed to increase or maintain a particular set of cognitive functions such as memory, attention, or executive functioning (Buschert et al., 2010; Clare \& Woods, 2004). This type of training has been employed with a range of clinical and healthy populations using different techniques (e.g., computerized; pencil/paper), and applications, like individual and group format (Vidovich \& Almeida, 2011). Cognitive training has been efficient in increasing the ability to learn face-name associations in patients with MCI of the amnestic type (Jean et al., 2010), improving the visual sustained attention in a variety of computerized cognitive exercises in patients with MCI (Finn \& McDonald, 2011), enhancing functional and cognitive performances (selective attention and phonemic verbal fluency) in patients with mild to moderate AD (Farina et al., 2002), and improving verbal memory, global cognitive functioning (Huntley et al., 2017) and semantic verbal fluency (Bahar-Fuchs et al., 2019) in people with mild AD.

Cognitive rehabilitation is an individualized approach that privileges teamwork among individuals with cognitive impairment, their families, and health professionals. It aims to identify relevant goals to the patient and strategies to achieve their focus on real-life situations (Buschert et al., 2010; Clare et al., 2003; Clare \& Woods, 2004). This type of intervention appears to have functional benefits in patients with AD (Takeda et al., 2012) and an additional cognitive and behavioral benefit in patients with MCI treated with cholinesterase inhibitors (Rozzini et al., 2007). Patients with MCI in a 4-week multicomponent cognitive rehabilitation program showed an improvement in activities of daily living, mood, and memory performance (Kurz et al., 2009).

Cognitive stimulation recommends the participation in activities that are aimed at a general improvement of cognitive and social functioning (Aguirre et al., 2011, 2014; Clare \& Woods, 2004). It emphasizes the benefits of group activities that can range from education, discussion, and debate, and problem-solving, to reality-orientation, reminiscence, and validation therapy (Vidovich \& Almeida, 2011). This strategy is one of the most studied and implemented cognitive approaches worldwide, being the one that gathers the most evidence regarding the improvement of cognition (Livingston et al., 2017). Several studies point to cognitive stimulation as a useful strategy to delay the progress of AD (Spector et al., 2003), to benefit cognitive function and aspects of well-being (Aguire et al., 2013; Woods et al., 2012), to decrease apathy and depressive symptoms in patients with mild to moderate AD (Niu et al., 2010), to improve cognitive performance and behavioral control in patients with mild to moderate dementia (Mapelli et al., 2013), and to enhance cognitive functioning and decrease depressive symptoms in people with dementia (Stewart et al, 2017). Some authors compare the cognitive benefits of cognitive stimulation to those of drugs, such as cholinesterase inhibitors (Knapp et al., 2006; Spector et al., 2008). Researchers acknowledge that the neuroprotective effects of cognitive stimulation in the promotion of brain plasticity and cognitive reserve are unknown. Still, they do not rule out the possibility that cognitive stimulation promotes neurogenesis (La Rue, 2010). Although most studies focus on the effects of cognitive stimulation in dementia, MCI has also been in the spotlight. MCI is recognized as a major health problem associated with an increased risk of developing dementia (Petersen et al., 2009). A review of 15 cognitive stimulation programs was performed in patients with amnestic MCI, and the results pointed to a substantial improvement in memory level, mood, and quality of life (Léonie et al., 2010). Besides, in elderly patients with cognitive decline, cognitive stimulation seems a potential and promising 
intervention to reduce symptoms of depression and depressive vulnerability (Niu et al., 2010; Raes et al., 2009).

According to the National Institute for Health and Care Excellence guidelines on dementia (NICE, 2006), all individuals with dementia must have the opportunity to participate in cognitive stimulation programs in structured groups, whether they are treated with anti-dementia drugs or not. According to these guidelines, cognitive stimulation is the only non-pharmacological intervention recommended to slow the progress of the disease's symptoms and maintain cognitive function.

Thus, cognitive stimulation seems to be a powerful intervention to use with patients with cognitive decline. Cognitive and functional improvements in people with MCI and dementia have been found (Aguirre et al., 2012; Spector et al., 2003, 2010; Woods et al., 2006; Buettner et al., 2011; Folkerts et al., 2018). This type of cognitive intervention was chosen for the program developed in this study.

\section{“Making a Difference” Program - a model to ImproveCog}

Among the various cognitive stimulation programs, one of the most recommended, effective, and available is "Making a Difference" which was created in the United Kingdom by Spector et al. (2001) being the Manual published in 2006 by Spector and colleagues. This program consists of 14 group sessions with the following themed activities: physical games, sound, childhood, food, current affairs, faces/scenes, associated words/discussion, being creative, categorizing objects, orientation, using money/clip adverts, number game, word game, and team games/quiz. The program was designed to run twice a week for 7 weeks. Each session has a 45 minutes length and a choice of activities, to cater to the interests and abilities of the group. The groups are run by two facilitators and usually have between 5 to 8 members that should ideally be at similar stages of dementia, so activities can be pitched accordingly.

The "Making a Difference" program showed benefits on global cognition and quality of life in patients with mild to moderate dementia, including those already in acetylcholinesterase inhibitor medication (Aguirre et al., 2013). There was also a significant enhancement on measures of delayed verbal recall, visual memory, orientation, and auditory comprehension (Hall et al., 2013). Although this therapy was originally developed for people with dementia, it has been used in patients with MCI with very positive results. It proved to be effective in maintaining the cognitive health of older people and can thus delay the installation of dementia and consequently improve the autonomy and independence of these patients (Apóstolo et al., 2011). This program has been adapted to different cultures, such as Italian, Sub-Saharan African, and Japanese, with similar results to those obtained in the original study (Capotosto et al., 2017; Paddick et al., 2017; Yamanaka et al., 2013), and was recently adapted to Portugal (Álvares Pereira et al., 2020a). The Portuguese adaptation of the program maintained its original structure but changed some of the activities due to cultural differences. To validate the program for the Portuguese population and test its effectiveness, a single-blind, multi-center, randomized controlled trial was conducted with 112 older people with mild to moderate dementia. The primary outcome measure was cognition and secondary measures were quality of life, communication, autonomy, anxiety, depression, and global functioning. The intervention group significantly improved relative to controls in cognition, communication, behavior, and global dementia rating. Quality of life, depression, and anxiety had no significant differences (Álvares Pereira et al., 2020b).

The Portuguese Reality of cognitive stimulation programs The investigation regarding nonpharmacological intervention for cognitive decline and dementia in Portugal is very scarce. To the best of our knowledge, there is only one analyzing the effects of a group cognitive stimulation program in Portuguese older adults with cognitive impairments with or without dementia (Alves et al., 2014). The program consisted of three sessions per week delivered for about 1.5 months, with two difficulty levels that could be alternatively used according to participants' cognitive level - MCI or mild to moderate dementia, as assessed according to compatible scores of the Global Deterioration Scale between 3 and 5. They compared two cognitive stimulation programs with different durations (17 versus 11 sessions). In both interventions, participants positively assessed their participation in the group and showed excellent adherence and completion rates, even in the absence of cognitive or functionality enhancements. It is important to note that there is a line of work regarding cognitive stimulation of individual application that is being made in Portugal, such as the MEMO+ Memory training program for mild Alzheimer Disease (Silva, 2013), that could also be complementary to group interventions.

Despite the few structured programs culturally adapted to Portugal and the minority of studies regarding the impact of cognitive stimulation programs, there are several computerized cognitive exercises available in the Portuguese market. These exercises such as RehaCom, CogniPlus, CogWeb, NEPUM, NeuronUp that aim to stimulate attention, memory, and executive functions (e.g., Almeida et al., 2016; Fernandes, 2015; Tedim Cruz et al, 2014), were initially developed for traumatic brain injury but they can be adapted to dementia. The problem with computerized cognitive exercises is that the majority 
of Portuguese older adults have a low level of education. Data from 2019 showed that 20\% of the Portuguese population over 65 years was illiterate and $52.8 \%$ only had 4 or less years of formal education (PORDATA, 2020) which can affect the capacity of people with cognitive impairment and dementia to make exercises through a computer. Given this potential problem with computerized exercises, it is thus useful to create pencil/paper programs culturally adapted to the reality of Portuguese patients. It is also important that the programs are designed to occur in a group format, which in addition to stimulating cognitive functioning can promote mutual help among patients and facilitate the acquisition of emotional and social skills that can contribute to greater adherence to the program. These particularities make it feasible to apply for cognitive stimulation programs in a health care institution, namely in the national health system, which despite material and human resources limitations would still be able to provide free care to a wide range of people with cognitive impairment at the same time with only two specialized professionals and few material resources. The individual application of cognitive stimulation programs, although may be advantageous for people with more severe deficits who might feel uncomfortable and more exposed in the group context, it has the disadvantage of losing social interaction and the support that only someone in a similar situation can give.

\section{Development of ImproveCog}

The development of a complex intervention like a cognitive stimulation program is a task that must be conducted very accurately within the right framework so the implementation of the program can be more likely to be effective on the target population. The Medical Research Council published a framework to guide researchers on the development, evaluation, and implementation of complex interventions. It consisted of a sequential phased approach including a preclinical phase (theory), phase I (modeling), phase II (exploratory trial), phase III (definitive randomized controlled trial), and phase IV (long-term implementation) (Campbell et al., 2000). This framework was later revised in order to address the limitations identified by providing a less sequential model of the process. Thus, complex interventions can be guided through four stages: Stage 1 - Development (preclinical phase and phase I), Stage 2 Piloting (phase II), Stage 3 - Evaluation (phase III), and Stage 4 - Implementation (phase IV) (Craig et al., 2008). The first three stages can be conducted simultaneously in an iterative process to better understand the problem, the intervention, and the evaluation (Campbell et al., 2007).

The development of a cognitive stimulation program requires the definition of the target population. The program developed in this study is designed for MCI, AD, and bvFTD. This selection is due to the prevalence of the clinical pathologies and their impact on the personal, familiar, and social life of patients and their families, and to the fact that we can act in a prodromal phase of dementia.

This study describes the process of development of a cognitive stimulation program (ImproveCog) for people with $\mathrm{MCI}$, mild to moderate $\mathrm{AD}$, and mild to moderate bvFTD, within the Medical Research Council framework. It only reports Stage 1 of this process focusing on the development process through the systematic search of the literature, as well as the qualitative studies for modeling intervention. As we can see in Figure 1, Stage 1 (Development) includes two steps: (a) the establishment of the theoretical and evidence basis of ImproveCog through a review of the existing cognitive stimulation programs and exercises and their efficacy which led to the first draft of ImproveCog (Pre-Clinical Phase), and (b) a qualitative modeling process through a focus group with health professionals that work with the target population of this program and individual interviews with patients with MCI and dementia (Phase I Modeling).

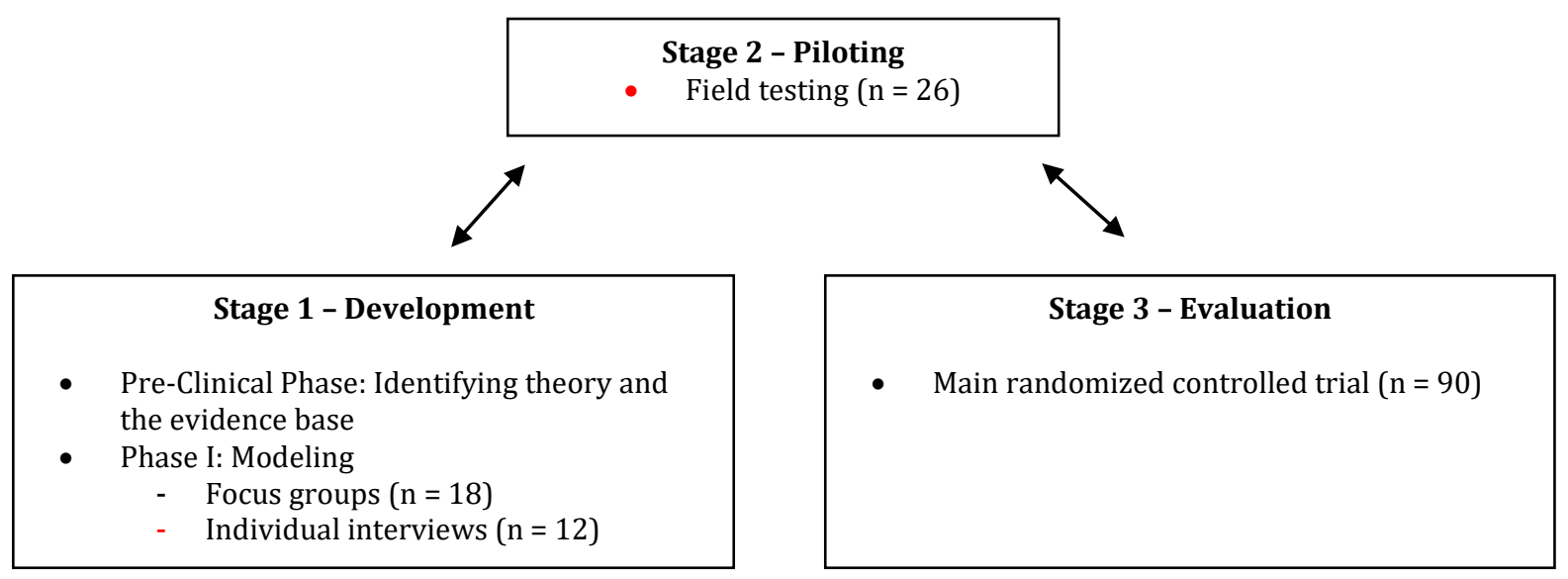

Figure 1. Development of ImproveCog within the Medical Research Council framework. 
It is important to note that this study was approved by different institutions. A confirmation of notification of treatment of clinical investigation data was obtained from the National Data Protection Commission in Portugal, and an authorization number 12791/2017 was obtained. It was requested authorization from the Psychology Unit of the Mental Health Department of the Local Health Unit of Matosinhos to carry out this project there, which was granted. The project was also submitted to the evaluation of the Local Health Unit of Matosinhos Ethics Committee and approval was obtained. It should be noted that this project was carried out in compliance with the Helsinki Declaration (1964) and subsequent changes.

\section{Preliminary Development (Pre-Clinical Phase)}

As mentioned earlier, cognitive stimulation is a useful strategy to deal with MCI and dementia. Many studies showed the positive impact of this kind of cognitive intervention in these populations (Léonie et al., 2010; Mapelli et al., 2013; Spector et al., 2003). However, is very difficult to compare those studies and to replicate them because the design of the studies is often not comparable, the materials are typically not accessible and the outcomes measured are highly variable. The aims of this first step were therefore to revise the theory behind cognitive stimulation, the mechanisms underlying its success, and the evidence supporting the strength of this strategy. This information was used to create the first draft of ImproveCog, a cognitive stimulation program for people with MCI, AD, and bvFTD. The method and results of the preliminary development of ImproveCog are described below.

\section{METHOD}

\section{Search strategy}

We carried out a literature search to identify relevant articles with theoretical and empirical data on cognitive stimulation. An online MEDLINE/PubMed, EBSCOHost (PsycINFO, PsycARTICLES) database search was performed between September 2015 and March 2017. Search expressions were: "cognitive training", "cognitive stimulation", "cognitive rehabilitation", "cognitive intervention", "cognitive stimulation therapy", "cognitive stimulation program", "neuropsychological rehabilitation", "memory training", "training", "intervention". All these terms were combined with "OR" and then the search was joined with "AND" for each of these concepts: "mild cognitive impairment", "MCI", "Alzheimer's Disease", "AD", "Frontotemporal Dementia", "FTD”, "behavioral variant Frontotemporal Dementia", "bvFTD", "dementia", "cognitive decline", "cognitive impairment". A manual book search for workbooks of cognitive stimulation programs and exercises was also performed.

\section{Data extraction and management}

The data included group cognitive stimulation therapies literature (e.g., D'Onofrio et al., 2015; Mapelli et al., 2013; Polito et al., 2015), cognitive stimulation exercises created to be delivered in individual or group format (e.g., Nunes \& Pais, 2006, 2007; Peña, 2010) and systematic reviews of literature about cognitive training/stimulation/rehabilitation (e.g., Knapp et al., 2013; Léonie et al., 2010; Tardif \& Simard, 2011). "Making a Difference" manuals (Aguirre et al., 2011; Spector et al., 2006; Yates et al., 2014) were also included. The data was revised according to its accessibility, efficacy for people with MCI and dementia, and type of presentation. Programs or exercises that were not accessible online (e.g., D'Onofrio et al., 2015; Mapelli et al., 2013), had not shown outcomes moderate to high in terms of cognition, humor, or quality of life in these populations (e.g., Alves et al., 2014; Polito et al., 2015), and were computerized (e.g., Finn \& McDonald, 2011; Tárraga et al, 2006) were not selected.

The benefits of the "Making a Difference" program have been consistently found on cognition and quality of life in patients with mild to moderate dementia (Aguirre et al., 2013; Hall et al., 2013) and with MCI (Apóstolo et al., 2011), across different countries (Capotosto et al., 2017; Paddick et al., 2017; Yamanaka et al., 2013), which makes it a relevant source of information. Based on the cognitive deficits more common in MCI, AD, and bvFTD, and using as a model the "Making a Difference" program and various cognitive exercises reviewed earlier, the cognitive stimulation sessions of ImproveCog were created. The sessions were adapted in order to be delivered weekly in a group format in a hospital environment. A set of original cognitive stimulation exercises to be individually executed at home by the participants between the sessions was also produced.

\section{Outcomes}

Based on the "Making a Difference" program, we created the first draft of ImproveCog, which consisted of twelve 90-min weekly sessions delivered by two facilitators to groups of 6 to 8 people with MCI, AD, and bvFTD. The number of sessions was reduced from 14 to 12 because programs lasting more than 12 weeks 
did not show any advantage over programs lasting 12 or fewer weeks (Léonie et al., 2010). The duration of each session was increased from 45 to 90 minutes due to the number of activities planned. The periodicity of the sessions was reduced from twice a week to weekly sessions due to the constraints of human resources and facilities in the Portuguese health care institutions and also because of the difficulties of participants in traveling to the hospital, too often dependent on family members for these trips. All sessions have a similar structure, composed of three moments. First, a warm-up activity involving the welcome of the participants, group song for enjoyment and social interaction, and orientation information and current affairs discussion (about 20 minutes). Second, themed mentally stimulating activities (about 50 minutes). The themed mentally stimulating activities in each session had two difficulty levels ( $A$ and $B$, being the first more cognitively challenging) that could be used according to participants' cognitive status. The themes and main activities suggested for each session can be seen in Table 1. These were presented in detail in a manual for group facilitators to use during the sessions. Finally, closing/summary with the collection of participant's feedback, delivery of cognitive stimulation exercises to be performed at home, group song, remembering the date of the next session, and farewell (about 20 minutes). The material needed for each session were created or acquired to fulfill the goals of each activity (e.g., cards with questions or pictures; bowling game; childhood toys).

Table 1. ImproveCog Sessions

\begin{tabular}{|c|c|c|}
\hline Session & Theme & Main Activities \\
\hline 1 & Physical games & $\begin{array}{l}\text { Play team games like Bowling and Jenga Tower that stimulate attention, action } \\
\text { planning, the share of information between participants' and mental calculus }\end{array}$ \\
\hline 2 & Sounds & $\begin{array}{l}\text { Identification and categorization of different kind of sounds; presentation of } \\
\text { different songs for theme and singer identification; play music using percussion } \\
\text { instruments; match sounds and corresponding pictures }\end{array}$ \\
\hline 3 & $\begin{array}{l}\text { Childhood \& } \\
\text { Family }\end{array}$ & $\begin{array}{l}\text { Fill out a printed sheet about childhood; building a family tree; demonstrate the } \\
\text { use of old-fashioned childhood toys; discuss actual and previous professions of } \\
\text { participants' and their families and the characteristic tools }\end{array}$ \\
\hline 4 & Food & $\begin{array}{l}\text { Planning a meal within a budget with real or replica groceries; categorize food; } \\
\text { taste food with reminiscent value; brainstorm food categories; name foods } \\
\text { beginning with a particular letter; discussion about food advertisements }\end{array}$ \\
\hline 5 & $\begin{array}{l}\text { Current affairs \& } \\
\text { Imagination }\end{array}$ & $\begin{array}{l}\text { Discuss issues from recent newspapers; imagining different situations and how to } \\
\text { react in that circumstances; tell a story about a picture }\end{array}$ \\
\hline 6 & Faces/Scenes & $\begin{array}{l}\text { Discuss photographs of famous people or local scenes; use pictures of past eras to } \\
\text { encourage reminiscence and compare the past with the present }\end{array}$ \\
\hline 7 & Associated words & $\begin{array}{l}\text { Identify the missing word in a number of phrases; identification of words in a } \\
\text { certain category; sing some songs; identify places in a map }\end{array}$ \\
\hline 8 & $\begin{array}{l}\text { Categorizing } \\
\text { objects }\end{array}$ & $\begin{array}{l}\text { Think of words in a category beginning with a letter; categorize objects; identify } \\
\text { the odd one out in a group of objects }\end{array}$ \\
\hline 9 & $\begin{array}{l}\text { Orientation \& } \\
\text { Planning }\end{array}$ & $\begin{array}{l}\text { Identify familiar places in a map; organize different activities in an agenda; sort in } \\
\text { sequence some pictures of actions; discuss the distance between places and } \\
\text { transport links }\end{array}$ \\
\hline 10 & Using money & $\begin{array}{l}\text { Guess the price of items or match the price tag with the object; discuss house } \\
\text { advertisements; show pictures of old and new coins and discuss changes in prices; } \\
\text { match pictures of objects with different kinds of payment methods }\end{array}$ \\
\hline 11 & $\begin{array}{l}\text { Numbers and } \\
\text { letters games }\end{array}$ & $\begin{array}{l}\text { Play games involving the recognition and use of numbers and letters; complete } \\
\text { crossword puzzles; guess how many items are in a container }\end{array}$ \\
\hline 12 & Quiz & $\begin{array}{l}\text { Play trivia quiz; discuss materials used in the previous sessions and participants' } \\
\text { feedback about the experience }\end{array}$ \\
\hline
\end{tabular}

ImproveCog, unlike "Making a Difference", has two components: group cognitive stimulation sessions and cognitive stimulation exercises designed to be individually performed at home. Thus, it was also created a manual with 330 pencil and paper cognitive stimulation exercises to be performed by participants at home between the group sessions. These exercises allow a daily stimulation of cognitive functions usually impaired in this population. This will generate a routine in participant's lives that we hope to be maintained after the end of the program. Combining different options like group activities and individual exercises performed at home may be more efficacious and enhance long-term engagement than just choosing one (Niederstrasser et al., 2016). The exercises were organized in five categories according to the target area: Orientation, Attention, Visuospatial processing, Memory, and Executive Functioning, with 66 exercises in each. Each participant is expected to perform at home five cognitive stimulation exercises on a daily basis (about 25 minutes), one for each cognitive area, in a total of 30 exercises in a week between each group session. The exercises are organized and labeled according to the 
day of the week they should be performed to guarantee that all participants perform the same exercises. Participants must perform the exercises individually but if necessary caregivers could explain and guide the task.

\section{Modeling (Phase I)}

Modeling a complex intervention prior to a full-scale evaluation is a valuable process to understand the intervention and its possible effects and may include qualitative testing through focus groups, case studies, interviews, or small observational studies (Campbell et al., 2007). The goal of this step is to assess the suitability of ImproveCog in terms of structure, group activities and materials, and individual exercises in order to implement the changes that might be indicated by this new evidence. For that, we conducted a focus group with health professionals and individual interviews with people with MCI and AD. Focus groups are a technique for collecting qualitative data from people with some kind of similarity in a group situation through a focused discussion, which can be used to obtain information on a topic of interest, stimulate new ideas, identify potential problems with a new program or generate impressions about programs (Silva et al., 2014). This technique was implemented with health professionals due to their theoretical knowledge of MCI and dementia, and their clinical experience with people with these conditions that could help to improve the program. Interviewing is the most common format of data collection in qualitative research. The individual interview is a valuable method of gaining insight into people's perceptions, understandings, and experiences of a given phenomenon and can contribute to indepth data collection. (Ryan et al., 2009). The use of this method with people that belong to the target population of the program intended to collect valuable information about the program, their perception about the structure and the adequacy of the activities and exercises, believing that their approval would mean that the program was more likely to be suitable for people with similar clinical conditions.

\section{FOCUS GROUPS}

\section{METHOD}

\section{Participants}

Eighteen Portuguese health professionals participated in five focus groups $\left(M_{\text {age }}=36.89\right.$ years, $S D=7.78$; 1 male; $M_{\text {education }}=18.22$ years, $S D=2.32 ; M_{\text {professional experience }}=12.89$ years, $\left.S D=6.94\right)$. The participants had different professions and specializations: 6 were Psychiatrists, 3 were Clinical Psychologists, 3 were Neuropsychologists, 3 were Nurses specialized in Psychiatry and Mental Health, 2 were Occupational Therapists and 1 was Neurologist. All participants had experience in working with patients with MCI, AD, and bvFTD on a daily basis. They were invited in their working place through personal or email contact and no one refused to participate.

\section{Procedure}

Five focus groups ( $n=3$ to 5 ) were held according to participant's availability: one group was composed of 3 Nurses; another by 3 Clinical Psychologists and 1 Psychiatrist; one by 5 Psychiatrists; one by 2 Occupational Therapists and 1 Neuropsychologist; and another one by 2 Neuropsychologists and 1 Neurologist. Each focus group was led by a Neuropsychologist or a master's student of Psychology in a quiet and spacious room and lasted from 60 to 90 minutes. The role of the moderator in these groups was to question, listen, keep the conversation on track and make sure that each participant had an opportunity to give their opinion. Three sessions took place in Hospital Pedro Hispano, Matosinhos Local Health Unit, one in Faculty of Psychology and Educational Sciences of University of Porto, and one in Centro Hospitalar São João, Porto. All sessions occurred between February and April 2018. First, the written informed consent was obtained for each participant and an anonymous sociodemographic and professional questionnaire was completed. Second, the two manuals of the first draft of ImproveCog (the one to use during group sessions and the one with exercises to be performed at home), along with the material for group sessions, were presented to participants for appraisal. Participants were given a script that guided them to pose questions targeting the program structure, the group activities, and the individual, at-home exercises. Some examples of the questions made in focus group sessions can be seen in Table 2. All sessions were audio-recorded and the facilitator took additional notes. The same procedure was used in the five focus groups. 
Table 2. Examples of questions used in Focus Group sessions

\begin{tabular}{ll}
\hline Theme & Questions \\
\hline Program structure & $\begin{array}{l}\text { "Do you consider the number of sessions and their duration appropriate? Do you propose } \\
\text { any changes?" } \\
\text { "The groups will consist of } 6 \text { to } 8 \text { people. Do you think it is an adequate size?" }\end{array}$ \\
$\begin{array}{l}\text { "Do these activities seem appropriate? Is the requirement level adjusted? What changes do } \\
\text { Individual exercises }\end{array}$ & $\begin{array}{l}\text { you propose?" } \\
\text { "Do you think the instructions are appropriate? Is the requirement level adjusted? Do you } \\
\text { propose any changes? Do you think another type of exercise should be included?" }\end{array}$ \\
\hline
\end{tabular}

\section{Analysis}

Audio recordings of the focus groups were transcribed. Data were analyzed and categorized according to the type of changes suggested by participants and their frequency.

\section{RESULTS}

The feedback gathered from the focus groups was sorted into four main categories according to the type of changes suggested, which are further detailed in Table 3. Regarding the structural issues, all participants agreed on the number of facilitators and members per group and the implementation of athome cognitive exercises between the weekly sessions. Still, most of the participants suggested some other changes. Seven participants from a total of eighteen participants suggested reducing the number of cognitive exercises to be performed at home. They didn't agree on the number of exercises that should be performed, ranging from 7 to 20 exercises a week. For example, one participant stated that "thirty exercises in a week it's a lot ... if they had a caregiver always by their side who would provide support maybe they could do it but it would still be difficult". The other seven participants recommended including a new theme in sessions. Two of them suggested addressing affectivity, recognition of emotions, and emotional expression, while the other five recommended adding daily life activities. Including a presentation session prior to the beginning of the program with the presence of the caregivers was indicated by five participants as a way of involving caregivers in this process, and let people feel less exposed and more protected. One participant even stated that "it would be a way of breaking the ice between the participants of the group, the caregivers would see that their support was crucial and it could even be a way of prolonging intervention in time through them". It was also recommended to change the order of sessions by four participants. All of them stated that physical games as session number one could potentially lead to a loss of interest in the program. Three of them even said to use some physical activities in other sessions instead of having a session fully reserved for this theme. Include a moment in each session to give feedback about the exercises made-at-home was indicated by three participants. Finally, one participant suggested reducing the duration of sessions to 50 minutes, while another one recommended changing the frequency of sessions to two sessions of 45 minutes each per week.

Changes focused on cognitive exercises were also greatly recommended. Participants recommended changing some exercises considered too difficult. For example, to replace words with images or to use exercises of form identification and recognition instead of drawing. Four participants also noted that only some exercises had an example item and suggested that all of them should start with an example. This would introduce and facilitate the task as well as create a predictive pattern across the different exercises. Three participants additionally suggested including new exercises and one advised to simplify the instructions.

Changes focused on group activities were pointed out by seventeen participants. Thirteen said that some activities were too difficult to be carried out by people with cognitive impairment and dementia and they should be simplified. For example, regarding session 8, one participant stated that "categorize objects in a large group could not work ... maybe it would be easier to present similar objects to all the participants and after they individually categorized them, then they would discuss their options ingroup". The inclusion of new types of activities, focusing on spatial orientation and sensory stimulation tasks, was recommended by four participants.

Finally, changes focused on editorial issues were addressed by only four participants. They included increasing the size of the font used in printed materials, putting only one exercise per page in the manual, and increasing line spacing in some exercises. 
Table 3. Type of Changes Suggested by Health Professionals to ImproveCog - Focus Group

\begin{tabular}{|c|c|c|}
\hline $\begin{array}{l}\text { Type of } \\
\text { changes }\end{array}$ & Health Professionals $(N=18)$ & $\begin{array}{c}\text { Number of participants } \\
\text { who endorsed the change }\end{array}$ \\
\hline \multirow[t]{7}{*}{$\begin{array}{l}\text { Structural } \\
\text { issues }\end{array}$} & $\begin{array}{l}\text { Decrease the number of cognitive exercises to be performed at- } \\
\text { home }\end{array}$ & 7 \\
\hline & Include a new theme in sessions & 7 \\
\hline & Reduce the duration of sessions & 1 \\
\hline & $\begin{array}{l}\text { Include a presentation session prior to the beginning of the } \\
\text { program }\end{array}$ & 5 \\
\hline & Change the order of sessions & 4 \\
\hline & $\begin{array}{l}\text { Include in sessions a moment to give feedback about the exercises } \\
\text { made-at-home }\end{array}$ & 3 \\
\hline & Change the frequency of sessions & 1 \\
\hline \multirow{2}{*}{$\begin{array}{l}\text { Group } \\
\text { activities }\end{array}$} & Change activities considered too difficult & 13 \\
\hline & Include new types of activities & 4 \\
\hline \multirow{4}{*}{$\begin{array}{l}\text { Cognitive } \\
\text { exercises }\end{array}$} & Change exercises considered too difficult & 10 \\
\hline & Include new exercises & 3 \\
\hline & Include an example for each exercise & 4 \\
\hline & Simplify the instructions & 1 \\
\hline \multirow{3}{*}{$\begin{array}{l}\text { Editorial } \\
\text { issues }\end{array}$} & Increase the size of the font used in printed materials & 2 \\
\hline & Put only one exercise per page in the manual & 2 \\
\hline & Increase line spacing in some exercises & 1 \\
\hline
\end{tabular}

\section{INDIVIDUAL INTERVIEWS}

\section{METHOD}

\section{Participants}

Twelve Portuguese-speaking individuals with MCI $(n=9)$ and $\mathrm{AD}(n=3)$ were individually interviewed $\left(M_{\text {age }}=67.50\right.$ years, $S D=9.01 ; 7$ females; $M$ education $=6.42$ years, $\left.S D=3.58\right)$. All participants had previously been evaluated by a Neuropsychologist and either a Neurologist or a Psychiatrist, who confirmed the clinical diagnosis. The participants were invited personally by the Neuropsychologist and no one refused to participate.

\section{Procedure}

Individual semi-structured interviews were carried out with people with MCI and AD. The interviews were scheduled according to their availability and were led by a Neuropsychologist. All interviews took place in Hospital Pedro Hispano, Matosinhos Local Health Unit, in a quiet and spacious room, and lasted from 45 to 60 minutes. They occurred between February and March 2018. First, the written informed consent was obtained for each participant and those with Alzheimer's Disease also for their caregivers. An anonymous sociodemographic and clinical questionnaire was then completed. Second, the two manuals of the first draft of ImproveCog (the one to use during group sessions and the one with exercises to be performed at home), along with the material for group sessions, were presented to participants for appraisal. The material used in the interviews and the focus group was the same. The interviewer used a script to guide the questions targeting the program structure, the group activities proposed on group sessions, and the individual activities ( at-home exercises). The interviews were audio-recorded and the interviewer took additional notes. The same procedure was used in all interviews.

\section{Analysis}

Audio recordings of the interviews were transcribed. Data were analyzed and categorized according to the type of changes suggested by participants and their frequency.

\section{RESULTS}

The feedback received from the interviews was organized into three core categories according to the type of changes suggested by the participants, as we can see in Table 4. Regarding the structural issues, all participants agreed on the periodicity of group sessions, as well as on the number of facilitators and members per group. Seven participants, in agreement with health professional's suggestions, expressed 
some concerns about the amount of cognitive exercises to be performed between the weekly sessions, "That's a lot of exercises, who will be able to do that? I think it's too much". Some suggested doing 12 exercises per week, while others indicated 15, 18, and even 20. Four participants recommended reducing the duration of sessions to 30 or 60 minutes instead of 90 minutes. Only one referred the need to decrease the number of sessions in case of a member of the group is still professionally active.

Changes focused on group activities were pointed out by five participants, four of which highlighted the importance of simplifying some activities considered too difficult, and one recommended changing the order of some activities.

Finally, changes focused on cognitive exercises were addressed by only two participants. One pointed out the need to simplify some exercises considered too difficult and other the importance of including new exercises.

Table 4. Type of Changes Suggested by People with MCI and mild AD to ImproveCog - Individual Interviews

\begin{tabular}{|c|c|c|}
\hline $\begin{array}{l}\text { Type of } \\
\text { changes }\end{array}$ & People with MCI and mild AD $(N=12)$ & $\begin{array}{l}\text { Number of participants who } \\
\text { endorsed the change }\end{array}$ \\
\hline \multirow[t]{3}{*}{$\begin{array}{l}\text { Structural } \\
\text { issues }\end{array}$} & $\begin{array}{l}\text { Decrease the number of cognitive exercises to be performed } \\
\text { at-home }\end{array}$ & 7 \\
\hline & Reduce the duration of sessions & 4 \\
\hline & Reduce the number of sessions if the participant works & 1 \\
\hline Group & Change activities considered too difficult & 4 \\
\hline activities & Change the order of some activities & 1 \\
\hline Cognitive & Change exercises considered too difficult & 1 \\
\hline exercises & Include new exercises & 1 \\
\hline
\end{tabular}

\section{DISCUSSION}

This study describes Stage 1 of the process of developing ImproveCog, a cognitive stimulation program for people with MCI, AD, and bvFTD, according to the Medical Research Council framework. This first stage of development encompass two steps: (a) the Pre-Clinical Phase, with the establishment of the theoretical and evidence basis of ImproveCog through a review of the existing cognitive stimulation programs and exercises and their efficacy which conducted to the first draft of ImproveCog; and (b) the Phase I - Modeling, that corresponds to a qualitative modeling process through a focus group with health professionals and individual interviews with people with MCI and AD.

A review of the theory behind cognitive stimulation, the existing cognitive stimulation programs and exercises, and the evidence supporting their efficacy was performed. The information was used to create the first draft of ImproveCog. This program has two components: group cognitive stimulation sessions and cognitive stimulation exercises designed to be individually performed at home, that are focused on specific cognitive functions usually impaired in the target population. Based on the "Making a Difference" program, we created the cognitive stimulation sessions, which consisted of twelve 90-min weekly sessions delivered by two facilitators to groups of 6 to 8 people with MCI, AD, and bvFTD. The option for a group cognitive stimulation program instead of an individual one was due to the benefits of group interventions, namely promotion of mutual help among patients, facilitation of the acquisition of emotional and social skills, and the fact that by intervening in several people simultaneously makes it a more viable option for health contexts. It was also created a manual with 330 pencil and paper cognitive stimulation exercises to be performed by participants at home between the group sessions. The exercises were organized in five categories according to the target area: Orientation, Attention, Visuospatial processing, Memory, and Executive Functioning, with 66 exercises in each. Each participant is expected to perform at home five cognitive stimulation exercises on a daily basis, one for each cognitive area, in a total of 30 exercises in a week between each group session.

The feedback received from health professionals and people with MCI and AD to the first draft of ImproveCog was generally positive. However, some important suggestions were made regarding structural and editorial issues, group activities, and cognitive exercises. The results are presented according to the frequency of participants who endorsed the change. Changes focused on structural issues were the most recommended by participants. Fourteen participants suggested reducing the number of exercises to be performed at home. To the best of our knowledge, does not exist an orientation of how many exercises should be performed at home on a daily basis. The aim of the program is to 
provide continuous cognitive stimulation during the 12 weeks, so it makes sense that participants have exercises to do every day. So, it was decided to maintain the realization of exercises 6 days a week but instead of 5, it will be 4 exercises per day. The exercises regarding "Orientation" will be left out of the final version of the program since this area is stimulated weekly in all sessions and daily by the caregivers. Seven health professionals recommended including a new theme in sessions. Given the importance of the themes suggested for the target population, in the final version of ImproveCog, there will be two new themes: Emotions (session 10) and Functionality (sessions 5 and 9). Emotions are an interesting topic and generally accepted to be addressed in a group by the inherent social support and interpersonal relationships that are created throughout the sessions. Furthermore, the ability to recognize emotion in facial expressions is affected at an early stage of cognitive impairment and might decline at an accelerated rate with the deterioration of cognitive function (Virtanen et al, 2017) what, combined with the fact that cognitive stimulation programs do not usually integrate this theme, makes this an innovative and valid option for this clinical population. Functionality, both basic and instrumental, is also a very relevant topic since its maintenance contributes to a better quality of life. In people with dementia, functional decline is already present, so the focus on this topic is quite relevant for the target population of the program. Five health professionals also suggested including a presentation session prior to the beginning of the program. They argued that this session could be useful to involve caregivers in this process and be a more welcoming way of introducing members of the group to this dynamic. In fact, this approach may even reinforce the adherence to the program and guarantee that people continue to be cognitively active after the end of the program. In the final version of ImproveCog, there will be a Session 0. Five participants suggested reducing the duration of sessions. However, since they agreed with the number of activities to be performed at each session, less than 90 minutes makes it impracticable, which is the reason why this suggestion will not be included in the final version of the program. Four health professionals suggested changing the order of sessions due to physical games being the number one session. To avoid a loss of interest in the program, in the final version, physical games will no longer be a session in itself but their activities will be properly distributed in other sessions. Although the impact of physical exercise is variable between studies (Livingston et al., 2017) some authors argue that it positively affects cognitive abilities and depressive symptoms in people with AD (e.g., Jurado et al., 2013; Knochel et al., 2012). For this reason and although the physical activities in this program are brief, we decided to integrate them in some sessions because they can be seen by participants as playful moments and facilitate the group dynamics. Three health professionals also considered it useful to include a moment in each session to give feedback about the exercises made at home. Since this modification could motivate group members and improve adherence to exercises, it will be considered in the final version of ImproveCog. Finally, one participant suggested changing the frequency of sessions to two sessions of 45 minutes each per week. This suggestion will not be taken into consideration since the option for one weekly session was made due to the usual availability of Portuguese health care institutions. Another participant suggested decreasing the number of sessions in case of a member of the group is still professionally active. The number of sessions used in cognitive interventions differs between studies (Gates \& Valenzuela, 2010; Li et al., 2011). Using the "Making a Difference" program as a model (Spector et al., 2001) the number of group sessions was already reduced from 14 to 12 . According to Léonie et al. (2010), programs that apply 6 to 20 sessions seem more cost-effective for clinical purposes, and the ones that last 12 or less weeks seem a good option to decrease the risk of attrition. Thus, the number of group sessions will be maintained in the final version of ImproveCog.

Changes focused on group activities were the second most recommended. The majority of health professionals proposed the simplification of some activities considered too difficult. However, this suggestion was only addressed by four people with MCI and AD. This discrepancy could represent an overestimation by health professionals of the difficulties experienced by patients. This concern was also made in the process of development of the "Making a Difference" program (Spector et al., 2001) that served as a model for ImproveCog. As result, the themed mentally stimulating activities proposed in each session have two difficulty levels that could be used according to participants' cognitive status. Despite this, a few activities were adjusted in order to guarantee that all group members could participate without feeling inadequate. Four health professionals emphasized the inclusion of new types of activities. The majority of suggestions corresponded to sessions that will be eliminated or changed in the final version of the program, but even so, we will include an activity regarding spatial orientation. The inclusion of this type of activity is due to the fact that spatial disorientation is a typical feature of dementia that has a great impact on the functionality of these people, and for that should be addressed in a cognitive stimulation program. Finally, only one participant recommended changing the order of some activities, which is not going to be considered in the final version of the program. According to the new themes and change of order suggested we decided to order the sessions as follow: 1 - Childhood \& 
Family; 2 - Sounds; 3 - Current affairs \& Imagination; 4 - Faces/Scenes; 5 - Basic functionality; 6 Associated words; 7 - Categorizing objects; 8 - Orientation \& Planning; 9 - Instrumental functionality; 10 - Emotions; 11 - Numbers and letters games; 12 - Quiz. We maintained the original order of sessions and the new sessions were included in the position of those who were to replace and integrate. For example, the "Using money" session was included in the "Instrumental functionality" session who took his place. "Emotions" was placed at the end of the program since the activities imply greater exposure and being comfortable with other participants.

Changes focused on cognitive exercises were also addressed by health professionals and people with MCI and AD. Eleven participants recommended simplifying some exercises considered too difficult. Although the majority of suggestions came from health professionals, we decided to revise all the exercises and simplify some of them in the final version of ImproveCog in order to guarantee that people do not get easily frustrated and unmotivated. Four participants suggested including new exercises. This will be considered in the final version of the program to guarantee that we have a diversity of exercises available to people with MCI and dementia that meet their personal tastes. Two types of modifications were also pointed out by health professionals. First, the suggestion to include an example for each exercise was addressed by 4 participants. This modification would ease the task as well as form a predictive pattern across the exercises. The suggestion will be introduced in the final version of the program. Second, the idea of simplifying the instructions was only made by one participant. This suggestion will not be included in the final version of the program due to the fact that no patient referred to this as an issue.

Finally, changes focused on editorial issues were only addressed by health professionals. Two participants recommended increasing the size of the font used in printed materials, two suggested putting only one exercise per page in the manual, and one said to increase line spacing in some exercises. Since no participant with MCI or AD valued this kind of modification, these will not be considered in the final version of ImproveCog.

Overall, ten changes suggested by health professionals and people with MCI and AD are going to be taken into account to revise the first draft of ImproveCog: (a) reduce the number of exercises to be performed at home; (b) include two new themes in sessions; (c) include a presentation session prior to the beginning of the program; (d) change the order of sessions; (e) give feedback about exercises madeat-home; (f) simplify some activities considered too difficult; (g) include new activities; (h) simplify some exercises considered too difficult; (i) include new exercises; and (j) include an example for each exercise.

To the best of our knowledge, this is the first study regarding the process of development of a cognitive stimulation program specifically developed for Portuguese older adults with cognitive impairments. The next step of the development and evaluation process of ImproveCog include a field testing of the program (Stage 2), that will collect information from caregivers and family members in order to enrich and complete the information given by participants and health professionals, and address topics such as patient recruitment and retention in order to inform a future definitive intervention for the evaluation of this program. The field testing (Phase II - Piloting) occurred also in 2018 and, along with Phase I completed in this study, allowed us to review the first draft of ImproveCog and create a final version. Between2019 and 2020 a main randomized controlled trial (RCT) was conducted (Stage 3; Phase III - Evaluation) to determine the effectiveness of ImproveCog and the results are currently being analyzed.

Although the implementation of the Medical Research Council framework and the rigorous development of an intervention represents best practice, this process does not guarantee the efficacy of the intervention or that the main full-scale trial will be unaffected by any challenges in the design, methods, and implementation. If the results of the main RCT are significant, the data collected from each phase in this process of development of the program is valuable to add some understanding of the mechanisms underlying its success. On the other hand, if the intervention does not succeed, the exhaustive nature of the development phase may give some indications into the potential reasons for this, offering an opportunity to improve the intervention.

\section{CONCLUSION}

The first stage of the process of development of ImproveCog was conducted, resulting in the production of the initial version of the program. Feedback was gathered from the focus groups and individual interviews to ensure the program was tailored to the needs of people with mild cognitive impairment and dementia.

The ImproveCog program although initially based on the "Making a Difference: An Evidence-based Group Program to Offer Cognitive Stimulation Therapy (SCT) to People with Dementia” (Spector et al., 
2006), is undoubtedly very different, presenting innovative features. Instead of based only on a global brain activation that has shown benefits mainly in terms of global cognition and quality of life, it was taking into account activities for the stimulation of specific executive functions (e.g., planning, working memory, cognitive flexibility, inhibitory control) reinforced in-home exercises, functionality (basic and instrumental activities of daily living), and emotions. We highlight the particular relevance of the executive functions that we know they decline most rapidly in the healthy aging process (e.g., Princiotta et al., 2015; Reuter-Lorenz et al., Jantz, 2016), are impaired in MCI (e.g., Kirova et al., 2015) and that is the first to signal different neurodegenerative conditions such as Frontotemporal and Alzheimer's dementias (e.g., Moreira et al., 2017). In addition to the benefits already associated with the stimulation of specific executive functions, it would be possible to act more effectively on functionality, which is both essential to maintain or delay the evolution of these neurodegenerative conditions. Moreover, emotion recognition impairments are well documented in Alzheimer's disease (e.g., Klein-Koerkamp et al., 2012) and other dementias such as behavioral variant frontotemporal dementia (e.g., Bora et al., 2016), and are most recently the subject of study in MCI (e.g., Bora \& Yener, 2017). In this way, the development process of the ImproveCog became increasingly different from Making a Difference, with unique characteristics and adapted to the health Portuguese settings and cultural issues.

The next step in the process of development of this complex intervention was to conduct a pilot study that, along with the findings on this study, allowed us to re-evaluate the first draft of ImproveCog and create a final version. A large-scale RCT was conducted to evaluate the effectiveness of the intervention.

\section{REFERENCES}

Aguirre, E., Hoare, Z., Streater, A., Spector, A., Woods, B., Hoe, J., \& Orrell, M. (2013). Cognitive stimulation therapy (CST) for people with dementia - Who benefits most? International Journal of Geriatric Psychiatry, 28(3), 284-290. https://doi.org/10.1002/gps.3823

Aguirre, E., Spector, A., \& Orrell, M. (2014). Guidelines for adapting cognitive stimulation therapy to other cultures. Clinical Interventions in Aging, 14(9), 1003-1007. https://doi.org/10.2147/CIA.S61849

Aguirre, E., Spector, A., Streater, A., Hoe, J., Woods, B., \& Orrell, M. (2011). Making a Difference 2: An evidence-based group programme to offer Maintenance Cognitive Stimulation therapy (CST) to people with dementia. Hawker Publications.

Aguirre, E., Woods, R., Spector, A., \& Orrell, M. (2013). Cognitive stimulation for dementia: a systematic review of the evidence of effectiveness from randomised controlled trials. Ageing Research Reviews, 12(1), 253-62. https://doi.org/10.1016/j.arr.2012.07.001

Almeida, I., Guerreiro, S., Martins-Rocha, B., Rocha, A., Vicente, S., Barbosa, F., \& Castro-Caldas, A. (2016). Impacto de um programa holístico de reabilitação neuropsicológica na qualidade de vida de pessoas com lesão cerebral adquirida. Psychologica, 58, 61-74. https://doi.org/10.14195/16478606_58 -2_4

Álvares Pereira, G., Nunes, M., \& Spector, A. (2020b). Validation of the Cognitive Stimulation Therapy (CST) for people with dementia in Portugal. Aging and Mental Health, 22, 1-10. https://doi.org/10.1080/13607863.2020.1836473

Álvares Pereira, G., Sousa, I., Meireles, L., Vicente, S., \& Nunes, M. (2020a). Fazer a Diferença - Programa De Terapia de Estimulação. Universidade Católica Editora.

Alves, J., Alves-Costa, F., Magalhães, R., Gonçalves, O., \& Sampaio, A. (2014). Cognitive stimulation for Portuguese older adults with cognitive impairment: A randomized controlled trial of efficacy, comparative duration, feasibility, and experiential relevance. American Journal of Alzheimer's Disease \& Other Dementias, 29(6), 503-512. https:/doi.org/10.1177/1533317514522541

American Psychiatric Association (2014). DSM-5. Manual de Diagnóstico e Estatística das Perturbações Mentais (5⿳亠丷厂 Edição). Climepsi Editores.

Apóstolo, J., Cardoso, D., Marta, L., \& Amaral. T. (2011). Efeito da estimulação cognitiva em idosos. Revista de Enfermagem Referência, III série, 5, 193-201. https://doi.org/10.12707/RIII11104

Bahar-Fuchs, A., Martyr, A., Goh, A., Sabates, J., \& Clare, L. (2019). Cognitive training for people with mild to moderate dementia. The Cochrane Database of Systematic Reviews, 25, 3:CD013069. https://doi.org/10.1002/14651858.CD013069.pub2

Bora, E., Velakoulis, D., \& Walterfang, M. (2016). Meta-analysis of facial emotion recognition in behavioral variant frontotemporal dementia: Comparison with Alzheimer disease and healthy controls. Journal of Geriatric Psychiatry and Neurology, 29, 205-211

Bora, E., \& Yener, G. G. (2017). Meta-Analysis of social cognition in mild cognitive impairment. Journal of Geriatric Psychiatry and Neurology, 30, 206-213. https://doi.org/10.1177/0891988717710337 
Buettner, L., Fitzsimmons, S., Atav, S., \& Sink, K. (2011). Cognitive stimulation for apathy in probable early-stage Alzheimer's. Journal of Aging Research, 2011(1), 1-6. https://doi.org/10.4061/2011/480890

Buschert, V., Bokde, A., \& Hampel, H. (2010). Cognitive intervention in Alzheimer disease. Nature Reviews Neurology, 6(9), 508-517. https://doi.org/10.1038/nrneurol.2010.113

Campbell, M., Fitzpatrick, R., Haines, A., Kinmonth, A. L., Sandercock, P., Spiegelhalter, D., \& Tyrer, P. (2000). Framework for design and evaluation of complex interventions to improve health. The British Medical Journal, 321(7262), 694-696. https://doi.org/ 10.1136/bmj.321.7262.694

Campbell, N. C., Murray, E., Darbyshire, J., Emery, J., Farmer, A., Griffiths, F., \& Kinmonth, A. L. (2007). Designing and evaluating complex interventions to improve health care. The British Medical Journal, 334(7591), 455-459. https://doi.org/10.1136/bmj.39108.379965.BE

Capotosto, E., Belacchi, C., Gardini, S., Faggian, S., Piras, F., Mantoan, V., Salvalaio, E., Pradelli, S., \& Borella, E. (2017). Cognitive stimulation therapy in the Italian context: Its efficacy in cognitive and noncognitive measures in older adults with dementia. International Journal of Geriatric Psychiatry, 32(3), 331-340. https://doi.org/10.1002/gps.4521

Clare, L., \& Woods, R. (2004). Cognitive training and cognitive rehabilitation for people with early-stage Alzheimer's disease: A review. Neuropsychological Rehabilitation, 14(4), 385-401. https://doi.org/10.1080/09602010443000074

Clare, L., Woods, R., Cook, E., Orrell, M., \& Spector, A. (2003). Cognitive rehabilitation and cognitive training for early-stage Alzheimer's disease and vascular dementia. Cochrane Database Systematic Review, 4, CD003260. https://doi.org/10.1002/14651858.CD003260

Craig, P., Dieppe, P., Macintyre, S., Michie, S., Nazareth, I., \& Petticrew, M. (2008). Developing and evaluating complex interventions: The new Medical Research Council guidance. The British Medical Journal, 337, a1655. https://doi.org/10.1136/bmj.a1655

D’Onofrio, G., Sancarlo, D., Addante, F., Ciccone, F., Cascavilla, L., Paris, F., Elia, A., Nuzzaci, C., Picoco, M., Grecco, A., Panza, F., \& Pilotto, A. (2015). A pilot randomized controlled trial evaluating an integrated treatment of rivastigmine transdermal patch and cognitive stimulation in patients with Alzheimer's disease. International Journal of Geriatric Psychiatry, 30(9), 965-975. https://doi.org/ 10.1002/gps.4247

Eleti, S. (2016). Drugs in Alzheimer's disease Dementia: An overview of current pharmacological management and future directions. Psychiatria Danubina, 28, 136-140.

Farina, E., Fioravanti, R., Chiavari, L., Imbornone, E., Alberoni, M., Pomati, S., Pinardi, G., Pignatti, R., \& Mariani, C. (2002). Comparing two programs of cognitive training in Alzheimer's disease: A pilot study. Acta Neurologica Scandinavica, 105, 365-371. https://doi.org/10.1034/j.16000404.2002.01086.x

Fernandes, V. (2015). Reabilitação cognitiva na lesão cerebral adquirida: Desenvolvimento $e$ implementação do programa CereBest. (Master Dissertation). Repositório Aberto da Universidade do Porto. https://repositorio-aberto.up.pt/handle/10216/90333

Finn, M., \& McDonald, S. (2011). Computerized cognitive training for older persons with mild cognitive impairment: A pilot study using a randomized controlled trial design. Brain Impairment, 12(3), 187-199. https://doi.org/10.1375/brim.12.3.187

Folkerts, A., Dorn, M., Roheger, M., Maassen, M., Koerts, J., Tucha, O., \& Kalbe, E. (2018). Cognitive stimulation for individuals with parkinson's disease dementia living in long-term care: Preliminary data from a randomized crossover pilot study. Hindawi, 2018, 1-9. https://doi.org/10.1155/2018/8104673

Gates, N., \& Valenzuela, M. (2010). Cognitive exercise and its role in cognitive function in older adults. Current Psychiatry Reviews, 12, 20-27. https://doi.org/10.1007/s11920-009-0085-y

Hall, L., Orrell, M., Stott, J., \& Spector, A. (2013). Cognitive stimulation therapy (CST): Neuropsychological mechanisms of change. International Psychogeriatrics, 25(3), 479-489. https://doi.org/10.1017/S1041610212001822

Huntley, J., Hampshire, A., Bor, D., Owen, A., Howard, R. (2017). Adaptive working memory strategy training in early Alzheimer's disease: Randomised controlled trial. The British Journal of Psychiatry, 210(1), 61-66. https://doi.org/10.1192/bjp.bp.116.182048

Jean, L., Simard, M., Wiederkehr, S., Bergeron, M., Turgeon, Y., Hudon, C., Tremblay, I., \& Reekum, R. (2010). Efficacy of a cognitive training programme for mild cognitive impairment: Results of a randomized controlled study. Neuropsychological Rehabilitation, 20(3), 377-405. https://doi.org/10.1080/09602010903343012

Jurado, M., Mataró, M., \& Pueyo, R. (2013). Neuropsicología de las enfermidades neurodegenerativas. Editorial Sintesis. 
Kirova, A. M., Bays, R. B., Lagalwar, S. (2015). Working Memory and Executive Function Decline across Normal Aging, Mild Cognitive Impairment, and Alzheimer's Disease. Biomed Research International, 1-9. https://doi.org/10.1155/2015/748212

Knapp, M., Iemmi, V., \& Romeo, R. (2013). Dementia care costs and outcomes: A systematic review. International Journal of Geriatric Psychiatry, 28(6), 551-561. https://doi.org/10.1002/gps.3864

Knapp, M., Thorgrimsen, L., Patel, A., Spector, A., Hallam, A., Woods, B., \& Orrell, M. (2006). Cognitive stimulation therapy for people with dementia: Cost-effectiveness analysis. The British Journal of Psychiatry, 188(6), 574-580. https://doi.org/10.1192/bjp.bp.105.010561

Knochel, C., Oertel-Knochel, V., O’Dwyer, L., Prvulovic, D., Alves, G., Kollmann, B., \& Hampel, H. (2012). Cognitive and behavioural effects of physical exercise in psychiatric patients. Progress in neurobiology, 96(1), 46-68. https://doi.org/10.1016/j.pneurobio.2011.11.007

Knopman, D., Boeve, B., \& Petersen, R. (2003). Essentials of the proper diagnoses of mild cognitive impairment, dementia, and major subtypes of dementia. Mayo Clinic Proceedings, 78(10), 12901308. https://doi.org/10.4065/78.10.1290

Kurz, A., Pohl, C., Ramsenthaler, M., \& Sorg, C. (2009). Cognitive rehabilitation in patients with mild cognitive impairment. International Journal of Geriatric Psychiatry, 24, 163-168. https://doi.org/10.1002/gps.2086

La Rue, A. (2010). Healthy brain aging: Role of cognitive reserve, cognitive stimulation, and cognitive exercises. Clinics in Geriatric Medicine, 26(1), 99-111. https://doi.org/10.1016/j.cger.2009.11.003

Léonie, J., Bergeron, M., Thivierge, B., \& Simard, M. (2010). Cognitive intervention programs for individuals with mild cognitive impairment: Systematic review of the literature. American Journal Geriatric Psychiatry, 18(4), 281-296. https://doi.org/10.1097/JGP.0b013e3181c37ce9

Li, J., Li, N., Li, B., Wang, P., \& Zhou, T. (2011). Cognitive intervention for persons with mild cognitive impairment: A meta-analysis. Ageing Research Reviews, 10, 285-296. https//doi.org/10.1016/j.arr.2010.11.003

Livingston, G., Sommerlad, A., Orgeta, V., Costafreda, S., Huntley, J., Ames, D., Ballard, C., Banerjee, S., Burns, A., Cohen-Mansfield, J., Cooper, C., Fox, N., Gitlin, L., Howard, R., Kales, H., Larson, E., Ritchie, K., Rockwood, K., Sampson, E., Samus, Q., Schneider, L., Selbaek, G., Teri, L., \& Mukadam, N. (2017). Dementia prevention, intervention, and care. Lancet, 390(10113), 2673-2734. https://doi.org/10.1016/S0140-6736(17)31363-6

Mapelli, D., Rosa, E., Nocita, R., \& Sava, D. (2013). Cognitive stimulation in patients with dementia: Randomized controlled trial. Dementia and Geriatric Cognitive Disorders, 3, 263-271. https://doi.org/10.1159/000353457

Massano, J. (2009). Demências. In M. Sá (Ed), Neurologia clínica: Compreender as doenças neurológicas (pp. 375-405). Edições Universidade Fernando Pessoa.

Moreira, H., Costa, A. S., Castro, S. L., Lima, C.F., \& Vicente, S. G. (2017). Assessing Executive Dysfunction in Neurodegenerative Disorders: The Role of Brief Neuropsychological Tools. Frontiers in Aging Neuroscience, 9, 1-13. https://doi.org/10.3389/fnagi.2017.00369

National Institute for Health and Care Excellence (2006). Dementia: Supporting people with dementia and their carers in health and social care. NICE clinical guideline. www.nice.org.uk/guidance/cg42

Niederstrasser, N., Hogervorst, E., Giannouli, E., \& Bandelow, S. (2016). Approaches to cognitive stimulation in the prevention of dementia. Journal of Gerontology \& Geriatric Research, 5, 1-12. https://doi.org/10.4172/2167-7182.S5-005

Niu, Y., Tan, J., Guan, J., \& Wang, L. (2010). Cognitive stimulation therapy in the treatment of neuropsychiatric symptoms in Alzheimer's disease: A randomized controlled trial. Clinical Rehabilitation, 24(12), 1102-1111. https://doi.org/10.1177/0269215510376004

Nunes, B., \& Pais, J. (2006). Doença de Alzheimer - Exercícios de Estimulação (Vol. 1). Lidel.

Nunes, B., \& Pais, J. (2007). Doença de Alzheimer - Exercícios de Estimulação (Vol. 2). Lidel.

Paddick, S., Mkenda, S., Mbowe, G., Kisoli, A., Gray, W., Dotchin, C., Ternent, L., Ogunniyi, A., Kissima, J., Olakehinde, O., Mushi, D., \& Walker, R. (2017). Cognitive stimulation therapy as a sustainable intervention for dementia in sub-Saharan Africa: Feasibility and clinical efficacy using a stepped$\begin{array}{llll}\text { wedge design. International 9sychogeriatrics, } & \text { 29(6), }\end{array}$ https://doi.org/10.1017/S1041610217000163

Peña, A. (2010). Estimulación cognitiva para adultos. Gesfomedia.

Petersen, R., Knopman, D., Boeve, B., Geda, Y., Ivnik, R., Smith, G., Roberts, R., \& Jack Jr, C. (2009). Mild cognitive impairment: Ten years later. Archives of Neurology, 66, 12, 1447-1455. https://doi.org/10.1001/archneurol.2009.266

Polito, L., Abbondanza, S., Vaccaro, R., Valle, E., Davin, A., Degrate, A., Villani, S., \& Guaita, A. (2015). Cognitive stimulation in cognitively impaired individuals and cognitively healthy individuals with a 
family history of dementia: Short-term results from the "Allena-Mente" randomized controlled trial. International Journal of Geriatric Psychiatry, 30(6), 631-638. https://doi.org/10.1002/gps.4194

PORDATA (2020). População residente com 15 a 64 anos e 65 e mais anos: Por nível de escolaridade completo mais elevado. https://www.pordata.pt/Portugal/Popula\%C3\%A7\%C3\%A3o+residente+com $+15+a+64+a n o s+e+$ $65+$ + + mais+anos+por+n\%C3\%ADvel+de+escolaridade+completo+mais+elevado+(percentagem)2266

Princiotta D., DeVries, M., \& Goldstein, S. (2015). Executive Functioning as a Mediator of Age-Related Cognitive Decline in Adults. In S. Goldstein \& J. A. Naglieri (Eds.). Handbook of Executive Functioning (pp. 143-155). Springer

Raes, F., Williams, J., \& Hermans, D. (2009). Reducing cognitive vulnerability to depression: A preliminary investigation of memory specificity training (MEST) in patients with depressive symptomatology. Journal of Behavior Therapy and Experimental Psychiatry, 40(1), 24-38. https://doi.org/10.1016/j.jbtep.2008.03.001

Reuter-Lorenz, P. A, Festini, S. B., Jantz, T. K. Executive Functions and Neurocognitive Aging. In K.W. Schaie \& S. L. Willis (Eds.). Handbook of the Psychology of Aging (pp.245-262). Elsevier.

Rozzini, L., Costardi, D., Chilovi, B., Franzoni, S., Trabucchi, M., \& Padovani, A. (2007). Efficacy of cognitive rehabilitation in patients with mild cognitive impairment treated with cholinesterase inhibitors. International Journal of Geriatric Psychiatry, 22, 356-360. https://doi.org/10.1002/gps.1681

Ryan, F., Coughlan, M., \& Cronin, P. (2009). Interviewing in qualitative research. International Journal of Therapy and Rehabilitation, 16(6), 309-314. https://doi.org/10.12968/ijtr.2009.16.6.42433

Silva, A. (2013) MEMO+ Memory training program for mild Alzheimer Disease.

Silva, I., Veloso, A., \& Keating, J. (2014). Focus group: Considerações teóricas e metodológicas. Revista Lusófona de Educação, 26, 175-190.

Spector, A., Orrell, M., Davies, S., \& Woods, B. (2001). Can reality orientation be rehabilitated? Development and piloting of an evidence-based programme of cognition-based therapies for people with dementia. Neuropsychological Rehabilitation, 11, 377-397. https://doi.org/10.1080/09602010143000068

Spector , A., Orrell, M., \& Woods, B. (2010). Cognitive stimulation therapy (CST): Effects on different areas of cognitive function for people with dementia. International Journal Geriatric Psychiatry, 25(12), 1253-1258. https://doi.org/10.1002/gps.2464

Spector, A., Thorgrimsen, L., Woods, B., Royan, L., Davies, S., Butterworth, M., \& Orrell, M. (2003). Efficacy of an evidence-based cognitive stimulation therapy programme for people with dementia. British Journal of Psychiatry, 183, 248-254. https://doi.org/10.1192/bjp.183.3.248

Spector, A., Thorgrimsen, L., Woods, B., \& Orrell, M. (2006). Making a difference 1: An evidence-based group programme to offer Cognitive Stimulation therapy (CST) to people with dementia. Hawker Publications.

Spector, A., Woods, B., \& Orrell, M. (2008). Cognitive stimulation for the treatment of Alzheimer's disease. Expert Review of Neurotherapeutics, 8(5), 751-757. https://doi.org/ 10.1586/14737175.8.5.751

Stewart, D., Berg-Weger M., Tebb, S., Sakamoto, M., Roselle, K., Downing, L., Lundy, J., \& Hayden, D. (2017). Making a Difference: A Study of Cognitive Stimulation Therapy for Persons with Dementia. Journal of Gerontological Social Work, 60(4), 300-312. https://doi.org/10.1080/01634372.2017.1318196

Tardif, S., \& Simard, M. (2011). Cognitive stimulation programs in healthy elderly: A review. International Journal of Alzheimer's Disease, 2011, 378934. https://doi.org/10.4061/2011/378934

Tárraga, L., Boada, M., Modinos, G., Espinosa, A., Diego, S., Morera, A., Guitart, M., Balcells, J., López, O., \& Becker, J. (2006). A randomised pilot study to assess the efficacy of an interactive, multimedia tool of cognitive stimulation in Alzheimer's disease. Journal of Neurology, Neurosurgery and Psychiatry, 77, 1116-1121. https://doi.org/10.1136/jnnp.2005.086074

Takeda, M., Tanaka. T., Okochi, M., \& Kazui, H. (2012). Non-pharmacological intervention for dementia patients. Psychiatry and Clinical Neurosciences, 66, 1-7. https://doi.org/10.1111/j.14401819.2011.02304.x

Tedim Cruz, V., Pais, J., Ruano, L., Mateus, C., Colunas, M., Alves, I., Barreto, R., Conde, E., Sousa, A., Araújo, I., Bento, V., Coutinho, P., \& Rocha, N. (2014). Implementation and outcomes of a collaborative multi-center network aimed at web-based cognitive training - COGWEB Network. Journal of Medical Internet Research Mental Health, 1(1), e2. https://doi.org/10.2196/mental.3840

Vega, J. N., \& Newhouse, P.A. (2014). Mild cognitive impairment: diagnosis, longitudinal course, and emerging treatments. Current Psychiatry Reports, 16(10), 490-490. https://doi.org/10.1007/s11920-014-0490-8 
Vidovich, M., \& Almeida, O. (2011). Cognition-focused interventions for older adults: The state of play. Australasian Psychiatry, 19(4), 313-316. https://doi.org/10.3109/10398562.2011.579973

Virtanen, M., Singh-Manoux, A., Batty, D., Ebmeier, P., Jokela, M., Harmer, C., \& Kivimäki, M. (2017). The level of cognitive function and recognition of emotions in older adults. PLoS ONE, 12, e0185513. https://doi.org/10.1371/journal.pone.0185513

Woods, B., Aguirre, E., Spector, A., \& Orrell, M. (2012). Cognitive stimulation to improve cognitive functioning in people with dementia. Cochrane Database Systematic Review, 15(2), CD005562. https://doi.org/10.1002/14651858.CD005562.pub2

Woods, B., Thorgrimsen, L., Spector, A., Royan, L., \& Orrell, M. (2006). Improved quality of life and cognitive stimulation therapy in dementia. Aging \& Mental Health, 10(3), 219-226. https://doi.org/10.1080/13607860500431652

World Health Organization (2019). Ten facts on dementia. http://www.who.int/features/factfiles/dementia/en/

Wortmann, M. (2012). Dementia: A global health priority - highlights from an ADI and World Health Organization report. Alzheimer's Research \& Therapy, 4(5), 40. https://doi.org/10.1186/alzrt143

Yamanaka, K., Kawano, Y., Noguchi, D., Nakaaki, S., Watanabe, N., Amano, T., \& Spector, A. (2013). Effects of cognitive stimulation therapy Japanese version (CST-J) for people with dementia: A single-blind, controlled clinical trial. Aging \& Mental Health, 17(5), 579-586. https://doi.org/10.1080/13607863.2013.777395

Yates, L., Orrell, M., \& Leung, P. (2014). Making a Difference 3: An evidence-based group programme to offer Individual Cognitive Stimulation therapy (CST) to people with dementia. Hawker Publications.

\author{
Historial do artigo \\ Recebido $\quad 08 / 12 / 2020$ \\ Aceite 26/03/2021 \\ Publicado 20/12/2021
}


ImproveCog, a cognitive stimulation program 